The operator now attempts to fix the uterus between his finger in the vagina, steadying the cervix, and a hand placed on the abdomen, a short distance above the symphysis, in such a way as to reach the fundus of the uterus. With the uterus in normal position with the vaginal finger in front and beneath the cervix, the fundus can easily be grasped as represented in Fig. 8 . If the fundus of the uterus is retroverted, it can be palpated by placing the vaginal finger behind the cervix and pressing the fundus down on it with the hand above. The operator, in making a systematic bimanual examination of the pelvic organs, must succeed in palpating and examining the exact position of the uterus before he can estimate the condition of diseased appendages, or expect to palpate the normal tubes and ovaries.

With the uterus thoroughly in hand, it is a simple matter to pass to the left or right, and examine the tube or ovary, or both, of the respective sides. If the tubes or ovaries are diseased and enlarged, it is comparatively easy, with practice, to grasp them between the hand on the abdomen and the finger in the vagina. When they are normal, and the abdominal walls of the woman are unusually thick, or unusually unyielding, they may not be palpated. Remember that the tube entering the horm of the uterus is soft and inelastic to the touch, that the ovary is deeper in the pelvis at a short distance from the uterus, spherical in shape, and elastic to touch.

Patients should be examined under an anesthetic, preferably ether, if conditions exist making it impossible to make a satisfactory diagnosis of the condition of the pelvis without.

\section{FOUR CASES OF CALCULI IMPACTED IN THE URETER.}

\section{NEPHRO-URETERECTOMY. ABDOMINAL URETERO-LITH-} OTOMY. VAGINAL URETERO-LITHOTOMY.

(From the Gynecological Clinic of the Johns Hopkins Hospital.) B. R. SCHENCK, M.D.

\section{BALTIMORE, MD.}

Among the first to recognize the importance of operative interference in cases of calculus impacted in the ureter was Henry Morris, ${ }^{1}$ of London, who as early as 1884 set forth the important principles governing the operative treatment of these cases. Although a considerable number of cases of ureteral stenosis from calculus had been reported clinically, and many in post-mortem protocols, there are but three brief records of operations, previous to Mr. Morris's paper.

In 1882 , Bardenhauer ${ }^{2}$ reported the successful removal of a stone from the ureter, by retroperitoneal ureterotomy, after which the ureter was closed with fine silk sutures. The other two cases are very briefly mentioned by Emmet, ${ }^{3}$ in both of which calculi were impacted in the vesical end of the ureter, one being removed by cystotomy, and the other by vaginal ureterotomy.

Morris's case was that of a woman of 55 years, with a history of renal colic for thirty months, who for six days had had almost complete anuria. On digital examination of the bladder, a calculus was felt impacted in the orifice of the left ureter, and Morris points out that a vesical ureterotomy could have been done had the proper instruments been at hand. In discussing this case, the author says: "I know of no other case in which a calculus has thus been detected during life, although Dr. Rawdon, ${ }^{4}$ of Liverpool, has reported an interesting case, in which a calculus impacted in the lower end of the ureter, was detected by a finger in the rectum, during life, and verified after death." The indications for digital exploration of the bladder, with a view to ureterotomy, are thus given. "As regards the question of surgical operation in which there is impaction in the ureter, there is no doubt but that in some of them the calculus could be removed by nephro-lithotomy or pyelo-nephrotomy. . . . and there is good reason to believe that with the more frequent resort to digital exploration of the kidney, through a lumbar incision, a calculus impacted in the upper end of the ureter will not infrequently be detected, and extracted through the loin. . . . . Calculi impacted in the intermediate parts of the ureter are practically beyond the reach of the surgeon." In view of the subsequent history of ureterotomy and the rapid advances which have since been made, these quotations from this early paper of Morris are of much interest.

Among the earlier cases of operation for removal of calculi impacted in the ureter, which have been much quoted throughout the literature on this subject, are those of extraperitoneal ureterotomy reported by Kirkham, ${ }^{5}$ Ralfe and Godlee, ${ }^{6}$ and Twynam ${ }^{7}$ in 1889, and Cabot $^{8}$ in 1890; those of intraperitoneal ureterotomy reported by Cullingworth ${ }^{9}$ in 1885, and Arbuthnot Lane ${ }^{10}$ in 1890 ; that of combined intraperitoneal and extraperitoneal ureterotomy by $\mathrm{Hall}^{11}$ in 1890; and that of vaginal ureterotomy by Cabot ${ }^{12}$ in 1890 .

As the total number of.operative cases in the literature is still less than ninety, very many of which are but briefly cited, it has seemed important to report, somewhat in detail, the cases which have come to operation in the gynecological department of the Johns Hopkins Hospital. To these are added the notes of a case recently occurring in the service of Dr. W. S. Halsted. The operation in each of these four cases was done by Dr. Howard A. Kelly.

CAse 1.-(Gynecological number, 6872.) Mrs. M. R., aged 29 years, was admitted to the service of Dr. Kelly, on April 25 , 1899 , complaining of pain in the left side, back and left lower abdomen, of three years' duration. The patient's family and past history was excellent; she had had four children and two miscarriages; the labors and puerperia were normal.

For the past three years she has suffered from intermittent attacks of dull aching pain in the left side and back, extending down into the left lower part of the abdomen. These attacks have occurred about once a week and usually last from three to four hours, being severe enough to require morphia for relief. The severest attack which she remembers was about one year ago, and this lasted about eight hours. The patient has noticed that the urine is very small in amount during an attack, and when the pain is unusually severe the secretion is almost completely suppressed. After the pain has passed away, however, the amount has sometimes been large, there having been voided as much as a quart in a short time. The urine has often been dark-colored, with a white sediment, but blood, brick-dust sediment or ealculi have never been noticed. Micturition has never been painful. She gives no history of chills, fever, jaundice or nausea. The appetite has always been good, but the bowels have been somewhat constipated. There has at times been some headache and vertigo, but these symptoms have never been excessive. There has been no loss of weight and strength has been well maintained.

On physical examination the patient was found to be a wellnourished, young-looking woman. The abdomen appeared quite natural and was everywhere soft on palpation, the edge of the liver, spleen and kidneys not being felt. On deep pressure there was some tenderness in the left flank, but this was not marked. She described, very minutely, the location and direction of the pain during an attack, indicating this by drawing a line, beginning just below the twelfth rib on the left side, at the posterior border of the quadratus Iumborum muscle, extending down to the crest of the ilium and thence anteriorally to a point just below the anterior superior iliac spine.

On admission the temperature was $98.6 \mathrm{~F}$, and the pulse 100 . The urine was clear yellow, with a specific gravity of 1017 , 
neutral, and contained a faint trace of albumin. Microscopically there were mucous cylindroids, a few pus cells, a few red blood-corpuscles and bladder epithelial cells, but no casts.

Previous to her admission to the hospital Mrs. R. had been seen by Dr. Kelly at his office, at which time a wax-tipped catheter was passed a few centimeters into the left ureter. On withdrawing the eatheter there were definite scratch marks on the polished tip, from which the diagnosis of calculous stenosis of the ureter was made.

The day before operation the right ureter was catheterized, in order to ascertain the condition of the right kidney. In thirty minutes 8 c.c. of practically normal urine were collected, thus demonstrating the efficiency of the supposedly sound side.

Operation was performed May 5, 1899, by Dr. Kelly, with peritoneal and extraperitoneal incisions, nephro-ureterectomy, and drainage.

A eatheter was passed into the left ureter and was distinctly felt to be gripped by, and then pass, one or more strictures in the lower part of the pelvis. The patient was then placed on the right side and an incision made midway between the crest of the ilium and the twelfth rib, anterior to the quadratus lumborum muscle, the peritoneum being opened just outside the descending colon. The right kidney and the upper part of the right ureter were palpated and found to be apparently normal. The left kidney seemed rather long, but normal, except for a deep depression in the center. The left ureter, on the contrary, was nodular, and enormously enlarged, being about the size of the descending colon. It was densely adherent at about the middle of the psoas muscle.

The enucleation was begun by shelling out the kidney, it being necessary to release numerous adhesions on all sides. After freeing and drawing the upper part of the kidney into the incision, the hilum was gradually tied off from above downward, taking care not to injure the large dilated pelvis. The renal vessels were tied separately with fine silk ligatures, divided, and the kidney freed. except around the pelvis, which was then slowly dissected free with scissors, as were about $5 \mathrm{~cm}$. ( 2 inches) of the upper part of the ureter. This portion of the ureter was so firmly adherent to the peritoneum, muscle and cellular tissue that it had to be separated with great care, many small vessels being tied with catgut. The incision in the abdominal wall was then closed with eatgut to each layer.

A second incision was now made, extraperitoneally, below the first and similar to that usually employed for tying the iliac artery. This extended mesially as far as the linea semilunaris, and was separated from the first incision by a bridge of tissue, about $6 \mathrm{~cm}$. (22/5 inches) wide. The enucleation of the ureter was then continued downward to the brim of the pelvis, and over the bifurcation of the iliac artery, where it was again found densely adherent, and had to be freed by a process of slow dissection. While continuing the separation downward along the floor of the pelvis the peritoneum was inadvertently torn, as was also the ureter, close by the bladder, at the point of stricture. At this point a rough ovoid calculus, $3.5 \mathrm{~cm}$. (1 2/5 inches) long and $1.5 \mathrm{~cm}$. (3/5 inches) in diameter, was found completely occluding the Iumen of the ureter.

The ureter was then cut off just below the calculus, and the kidney and ureter removed in one piece, the ureteral stump being closed over with catgut sutures. Considerable pus had escaped from the torn ureter, and, after thorough irrigation, a gauze drain was inserted from above, meeting another placed through the vaginal vault. A third drain was placed in the position of the kidney, and the remainder of the wound closed with interrupted silkworm and catgut sutures.

Ether anesthesia was used, the time of the operation being three hours and twenty minutes. The patient stood the operation well, the pulse at the end being 124 to the minute.

Five hours after, there was a condition of profound shock, requiring most urgent stimulation, but thereafter the convalescence was entirely satisfactory. The drainage tracts gradually contracted down, the remainder of the wound having healed per primam. At the time of discharge from the hospital, the twenty-sixth day, there still persisted a sinus, the size of the little finger, extending 10 to $11 \mathrm{~cm}$. (4 inches) down into the pelvis, and discharging a small amount of thin purulent fluid. There was absolutely no pain and the general condition was excellent.

A letter recently received from Mrs. $R$. states that she is entirely free from pain, has gained twenty-seven pounds in weight, and is in excellent health.
ABSTRACT FROM PHE PATHOLOGICAL REPORT (NO. 3127).

The kidney is altered in shape and is somewhat enlarged, being $13.5 \mathrm{~cm}$. (5 4/5 inch) long. At the middle of the convex border is a triangular depression $1.5 \times 2.5 \mathrm{~cm}$. (1/2xl inch) in size and $5 \mathrm{~mm}$. ( $1 / 5 \mathrm{inch}$ ) in depth, whose base is rough and consists of dense fibrous tissue. The kidney substance itself is rough, presents well-marked lobulation, is slightly granular and the superficial blood-vessels are dilated. 'The cortex is dense in consistency, while the pelvis is filled with fluid.

On section, the upper portion is congested, but fairly normal, while at the lower pole the cortical and medullary pertions are ill defined and the congestion less marked. Where the de pression was noted externally, the renal substance has been replaced by a band of dense fibrous tissue, averaging $5 \mathrm{~mm}$. ( $1 / 5$ inch) in thickness. The pelvis is moderately dilated, its mucosa pale and smooth, except over the apices of the pyramids, where it is much congested.

The ureter is represented by a large, sacculated cylinder, $20 \mathrm{~cm}$. ( 8 inches) long, and averaging $3 \mathrm{~cm}$. ( 1 1/5 inches) in diameter. It is slightly kinked, and contracted at the junction of the first and second quarters, and again at the third and fourth, giving it somewhat the appearance of a string of sausages. The whole is enveloped in a mass of adhesions, containing lobules of fat. On pressure, it is partly fluctuant and partly firm and resistant.

On section, the ureter is of unequal caliber, presenting irregular intervals of dilatation and contraction. The lumen varies from $5 \mathrm{~mm}$. ( $1 / 5 \mathrm{inch})$ to 1.5 (3/5 inch) in diameter The walls are greatly thickened and edematous, in some places reaching $1.5 \mathrm{~cm} .(3 / 5 \mathrm{inch})$ in thickness. The mucosa is at intervals smooth, at others corrugated. In places it is anemic and thinned out, and in others congested and edematous. The lumen contains a small amount of seropurulent fluid.

Microscopically the kidney shows the changes commonly seen in advanced, chronic interstitial nephritis. Sections of the ureter show it to be ensheathed in a mass of adipose, and newly-formed connective tissue, rich in blood-vessels of moderate size, and showing a general leucocytic infiltration. The walls are greatly thickened, owing in part to hypertrophy of the smooth muscle, but chiefly to a thick tunic of connective tissue, external to the muscular coats. This tissue is very edematous and contains several foci of round cell infiltration. This coat in places is 7 to $8 \mathrm{~mm}$. ( $1 / 3$ inch) in thickness.

The mucosa lining the canal is. also thickened. It presents the usual folds, and is covered in general by intsict, transitional epithelium. Here and there over the summits of the folds it is thin, sometimes only one layer of poorly staining cells remaining, while at one or two points the surface is de nuded of its epithelium. In sections taken at the level of the impacted calculus the lumen is dilated, the folds of the mucous membrane flattened, and the mucosa thinner than elsewhere.

The calculus is ovoid in shape, with tapering ends. The surface is rough, crystalline and of a yellowish-brown color It measures $3 \times 1.5 \times 1.3 \mathrm{~cm}$. $(12 / 5 \times 3 / 5 \times 2 / 5$ inch $)$, and consists principally of calcium carbonate, with small quantities of calcium and magnesium phosphate.

CASE 2.-(Gynecological number 6598.) Miss K., aged 37 years, was admitted to the service of Dr. Kelly, Johns Hop kins Hospital, Dec. 22, 1898, complaining of a painful swelling in the right side of the abdomen. Except for irregular menstruation, she had always been well and strong until eight years before coming to the hospital, when she first noticed a swelling in the lower part of the right side, which she describes as having been about six inches long and four inches wide. This swelling came on rather gradually, attaining its maximum size in about one week, when, after persisting for three or four days, it gradually disappeared. During this time she felt miserable, was nauseated, had a constant frontal headache and a dull pain in the abdomen, with now and then sharp cramps in the region of the swelling. She does not remember having had fever, and does not recall having passed at any time either unusually small or unusually large amounts of urine.

The subsequent history has been that of a repetition of similar attacks, usually at intervals of three or four months. For the last three years, however, the tumor has been reappearing every three weeks, and for the past six weeks it has remained permanent. During the first few days of this last reappearance the patic $\mathrm{it}$ had an unusually sharp attack of pain in the right side, was much nauseated, felt feverish and had slight diarrhea. Micturition has never been painful, and there has been no hematuria.

On admission to the hospital the temperature was $99.2 \mathrm{~F}$. 
and the pulse 100. The heart and lungs were normal. The abdomen was unsymmetrical, the right half and right flank being more or less completely occupied by an area of elevation, which rose to within $1 \mathrm{~cm}$. (1/5 inch) of the costal margin, and extended $6.5 \mathrm{~cm}$. (21/2 inches) toward the symphysis pubis. Its greatest prominence was at the level of, and $1 \mathrm{~cm}$. to the right of, the umbilicus. On palpation no definite tumor mass could be made out, one simply feeling a distinct area of resistance, extending downward from below the costal margin. The percussion note over this area was flat. Rectal and vaginal examinations were negative.

Urine on admission: The eatheterized specimen was smoky, witn a small amount of reddish percipitate, consisting of a large number of red blood-corpuscies, a few leucocytes and a few epithelial cells from the bladder; specific gravity, 1023; reaction acid. A trace of albumin was present; sugar test negative.

Operation, Dec. 24, 1898, was performed by Dr. Kelly, with abdominal uretero-lithotomy, suture of the ureter with fine silk and drainage.

An oblique incision, $20 \mathrm{~cm}$. ( 8 inches) long was made over the prominence of the tumor, beginning posteriorally and extending downward and to the left. The peritoneum was opened, exposing the large dilated pelvis of the right kidney, pointing out anteriorally, the kidney cortex, which was only $.5 \mathrm{~cm}$. (1/2 inch) thick, being confined to the upper and outer pole. A free incision was then made into the lower pole of the sac, evacuating 370 c.c. of pale urine, and with it a little flat, dark colored stone $6 \mathrm{~mm}$. ( $1 / 5$ inch) long. The sac was so large and irregular that a search for the opening into the ureter was unavailing. The colon was then pulled over and a further search on the outside of the sac made without result, until the ureter was picked up, with the ovarian vessels, at the pelvic brim, pulled down in order to make it tense, and then followed up step by step into the cellular tissue behind the colon.

When a point $3 \mathrm{~cm}$. ( $11 / 5$ inches) below the reral orifice was reached, two stones were plainly seen and felt, firmly lodged in the lumen of the ureter. The calculi were 12 to 14 $\mathrm{mm}$. ( $1 / 2$ inch) long, the lower one being a little the larger. The ureter below them was normal in size and appearance. As suggested by Israel, an attempt was now made to push the stones up into the pelvis of the kidney, in order to remove them through the pelvic opening already made, but ihis was impossible without tearing the ureter.

The ureter, at the level of the impaction, was then freed of all its connective tissue envelope, and by means of a rope of gauze passed beneath it, pulled down within easier reach. After making a longitudinal incision, through the ureteral wall over the lower third of the lower stone, an unsuccessful attempt was made to dislodge it. As it could not be moved, the incision was carried upward, exposing the whole stone, when it was lifted out with difflculty, on account of the firm adhesions to the ureteral wall. The upper stone could not be pulled down and extracted through this opening, it being necessary to continue the ureteral incision until it was $3.5 \mathrm{~cm}$. (1 2/5 inches) long. The second calculus, also adherent, was then picked out, leaving behind a roughened ureteral wall, which was considerably thickened at this level.

The incision in the ureter was then closed with twelve fine silk sutures, placed about $3 \mathrm{~mm}$. (1/8 inch) apart, great care being taken not to encroach upon the lumen of the tube. The opening in the renal pelvis was sutured with interrupted stitches of fine silk, and the wound closed, with lateral drainage from the peritoneal cavity.

As an anesthetic 420 gms. of ether were given, the time of operation being two hours and four minutes. Throughout the operation the condition of the patient was alarming, the respirations being shallow and the pulse weak and rapid140 to the minute. The general condition, however, was somewhat improved by a submammary infusion of salt solution.

The fluid evacuated from the hydronephrotic sac measured 370 c.c. ( $12 \mathrm{oz}$.), had a specific gravity of 1006 , and was neutral in reaction. It contained a trace of albumin, no sugar, and its urea equalled $.0014 \mathrm{gms}$. per c.c. Microscopically there were a few red blood-corpuseles and leucocytes.

The patient rallied well from the operation, her highest temperature being $1.01 \mathrm{~F}$., on the evening of the third day. During the first week after operation the urine contained considerable quantities of blood, but this gradually diminished, and at the time of her discharge the analysis was as follows: Dark amber, with a small amount of reddish percipitate, consisting of red blood-corpuscles, leucocytes, ammonium urate and triple phosphate crystals, and a few hyaline casts; specific gravity, 1015; reaction, neutral; no albumin; no sugar.
The gauze drain was gradually removed, beginning on the sixth day. Except at the point of drainage, the wound healed per primam, and the subsequent convalescence was uneventful. She was discharged from the hospital on the thirty-first day after the operation.

Since leaving the hospital the patient's health has been excellent. She has had no recurrence of the attacks of colic from which she sutfered previous to the operation.

CASE 3.- (Gynecological number 7762.) Mrs. J., aged 32 years, the mother of two children, was admitted to the service of Dr. Kelly, April 24, 1900, complaining of a swelling in the left llank and of pyuria of long duration. Mrs. J. dated her illness back eleven years, but previous to that had always enjoyed excellent health. During these eleven years she has had repeated attacks of renal colic, most frequently on the left side, but occasionally on the right. These attacks have varied in frequency, sonetimes coming as often as once a month, the last one, however, having been about eighteen months ago, when there was a severe attack of pain on the right side. At this time she was examined by J Dr. Malloch, of Hamilton, Ontario, who discovered a tumor in the region of the left kidney.

For many year's there has been more or less pus in the urine; sometimes the amount is very large and again the urine becomes much clearer for a time. Whether the size of the swelling in the left side corresponds to the amount of pus in the urine the patient does not know. She has never ncticed any hematuria, but has been told that there was blood in the specimens examined microscopically. Dr. Malloch also reports that no tubercle bacilli have ever been found, although repeatedly examined for. So far as known, no calculi have ever been voided. Urination seemed to be normal, although possibly somewhat increased in freqency. Mrs. J. thought that the tumor had increased somewhat in size during the past year, but at this time she suffered no pain, and eame to the hospital only because advised to do so by her physician.

On examination the patient was found to be a slight woman, fairly well nourished, but with a somewhat sallow complexion. The lips and mucous membranes were pale, the hemogiobin being but 60 per cent.

The abdomen was somewnat asymmetrical, the left fank line bulging abruptly under the costal margin, causing the floating ribs to be displaced laterally. Toward the median line another swelling was apparent, most prominent in the parasternal line, just to the left of the umbilicus and extending downward to within $5 \mathrm{~cm}$. ( 2 inches) of Poupart's ligament. On palpation a distinct tumor could be felt, extending from beneath the twelfth rib on the left, mesially to within $2.5 \mathrm{~cm}$. ( 1 inch) of the median line and downward to within $5 \mathrm{~cm}$. (2 inches) of Poupart's ligament. 'This mass was semi-fluctuint, rounded, and at a point half way between the costal margin and the umbilicus a distinct notch could be felt. The tumor was quite freely movable, descended about $3 \mathrm{~cm}$. (1 $1 / 5$ inches) on deep inspiration, and could be pushed for a distance of $5 \mathrm{~cm}$. (2 inches) upward and to the left toward the position of the left kidney. It was slightly sensitive on deep pressure.

The abdomen was everywhere tympanitic, except in the region of this mass, which was uniformly dull on percussion. The right kidney was distinctly palpable. No induration nor tenderness could be made out along the course of eitlier ureter.

On April 25, Dr. Kelly examined the bladder and catheterized both ureters, according to his method with the open cystoscope and air-distended bladder. A wax-tipped catheter was first passed into the left ureter and up into the renal pelvis. The urine began to flow in thirty seconds, and in five minutes 15 c.c. had collected. When the catheter was withdrawn seratch marks were plainly visible on the wax tip.

The right side was then catheterized, also with a catheter tipped with wax. Soon after entering the ureter a partias obstruction was met, but after careful manipulation the eatheter could be pushed up into the pelvis of the kidney. On withdrawing the stylet urine immediately began to flow, and in thirty-five seconds 60 e.e. were obtained, thus lemonstrating a definite dilatation of the upper ureter and renal pelvis. On withdrawing the catheter it was found to be engaged until within $12.5 \mathrm{~cm}$. of the external ureteral orifice. Deducting $4 \mathrm{~cm}$. (the length of the urethra) and $2 \mathrm{~cm}$. (the distance from the internal urethral orifice to the ureteral opening) the obstruction was computed to be $6.5 \mathrm{~cm}$. $(23 / 5$ inches $)$ from the bladder. The wax tip, after withdrawal, showed several long, deep stratch marks.

Cultures were made from the separated urines and from the bladder. All three showed a pure culture of the bacillus capsulatus of Friedlander.

The urinary examinations were as follows: Average amount 
voided in twenty-four hours previous to the operation, 1300 c.c.; light yellow, diffusely cloudy; specific gravity, 1008; acid; no sugar; albumin present to the amount of one-tenth of 1 per cent. Microscopically, very many pus cells were seen, no casts, no red blood-corpuscles, and no crystalline elements. The urea equalled $3 \mathrm{gms}$. to the liter.

Urine from the right kidney: April 25, light yellow, with a flocculent white precipitate; acid; no sugar; a trace of albumin. Microscopically, pus cells and a few red blood-corpuscles were seen, but no easts and no crystals. The urea equalled 4 gms. to the liter.

Urine from the left kidney: Very pale, diffusely cloudy; faintly acid; no sugar; albumin present in much larger quantities than on the right side, but the amount cbtained was not sufficient for a quantitative test. The precipitate of pus was also much greater than on the opposite side. Microscopically, there were many pus cells, large epithelial cells from the renal pelvis, and a few red blood-corpuscles; no casts and no crystals. The urea equalled $21 / 4$ gnis. to the liter.

On April 27, a radiograph was taken by Dr. C. L. Leonard, of Philadelphia, who happened to be present in Baltimore at this time. The plate distinctly showed a shadow in the region of the left kidney and another, about the size of an almond, on the right side. This appeared to be located in the position of the right ureter, at the point where it crosses the pelvic brim, and therefore appeared higher up than the position made out by the catheter. As was later shown, this error was due to the obliquity of the rays.

Operation was performed April 28, 1900, by Dr. Kelly, with lett lumbar nephrolithotomy.

An incision $8 \mathrm{~cm}$. (3 $1 / 5$ inches) long was made through the skin and subcutaneous fat, extending downward and forward, directly over Petit's triangle. By pushing the external oblique muscle forward and the latissimus dorsi backward the fibers of the internal oblique muscle were exposed. By separating these fibers the thin fascia of the transversalis musele eame into view, and was incised, exposing the perirenal fat around the lower third of the kidney. After tearing away a portion of this fat the renal pelvis was aspirated, considerable purulent urine withdrawn, and a calculus demonstrated. A blunt artery ciamp was then thrust through the kidney substance, the opening thus made being siow y enlarged by blunt dissection. A large denditic calcusus was then removed, the stone being partially esushed during its extraction. This was followed by very tree hemorrhage from the renal parenchyma. lailing to control this with sutures, the incision was tightly packed with gauze and a firm gauze compress applied to the wound, a portion of which had been closed with inter'upted silkworm-gut sutures.

Chloroform was used for anesthesia, the time of operation being twenty-five minutes. The pulse at the end of operation was 64 to the minute.

'I he convalescence from the operation was very satisfactory. For three days there was an abundant discharge of urine fron. the sinus, the amount, however, decreasing until the packing was removed on the tenth day. The opening of the sinus caused the amount to increase, but after several days it began to diminish, and on the twenty-third day there was practically nonc, the patient voiding 2190 e.c. ( 70 ounces). 'she temperature on the third day touched 103 F., thereafter being about 100 until the twelfth day, when it became normal and remained so. The urine following this operation had practically the same characteristies as that previously passed.

On account of the profuse bleeding which took flace during the operation, it was not deemed best to remove the calculus from the right ureter at that time. On the twenty-sixh day, however, the patient's condition was excellent, the pulse being 70 and the temperature $98.4 \mathrm{~F}$., and the second operation was done.

Second Operation.-On May 23, 1900, Dr. Kelly performed an exploratory laparotomy with vaginal ureterotomy.

Before beginning the operation both ureters were catheterized. The left ureter was patulous and urine flowed freely from the catheter. On the right side the same resistance was met as at the previous examination. The right catheter was left in place.

An incision $12 \mathrm{~cm}$. (5 inches) long was made in the median line of the abdomen. The left ureter was found to be of normal size, there being no evidence of thickening. On the right side the ureter above the pelvic brim felt normal, and careful palpation of the kidney revealed no stone. The right tube and ovary were adherent over the ureter low down in the pelvis. After the separation of these adhesions the calculus was found to be located about $6 \mathrm{~cm}$. $(23 / 5$ inches $)$ above the vesical opening. A small bulb syringe was now attached to the cathe- ter, which had been left in the ureter, and the pelvis and ureter were distended with about 50 c.c. of boric solution, in order to move, if possible, the stone into a position more advantageous for extraction. It was found, however, to be adherent and could not be loosened. With the assistant's hand in the abdomen, locating and fixing the stone, it could be felt through the vaginal vault. An incision was therefore made with the sharp-pointed scissors through the vault of the vagina, and the tissues separated until the thickened ureter was encountered. This was then slit open with the "alligator" scissors and the calculus extracted with stone forceps. No attempt was made to suture the slit in the ureter.

The abdominal incision was then closed and a small iodoformized gauze drain placed, from the vagina, against the ureteral catheter, which was left in place.

Chloroform was used, the time of the operation being forty minutes. 'The pulse, at the end of the operation, was 68 to the minute.

The catheter was allowed to remain in the ureter for sixteen hours, and during this time it drained 650 c.c. of urine. It then became occluded and there was leakage into the vagina. However, this discharge ceased when the catheter was withdrawn and there was absolutely none until the gauze pack was removed, on the ninth day. There was then leakage until the fifteenth day, when it entirely ceased. In every respect the convalescence was perfectly satisfactory and the patient left the hospital on the twenty-seventh day. On that day the urinary analysis was as follows: Amount, 1920 c.c.; light straw color, slightly cloudy, with a small amount of sediment composed of pus cells and epithelial cells; specific gravity, 1010; reaction, acid; a faint trace of albumin.

The calculus removed from the right ureter was the size and shape of an almond. Its surface was rough and of a brownishblack color. 'The weight was 1.25 gms. (19 grains) and the dimensions $1.8 \times 0.8 \times 0.5 \mathrm{~cm}$.

The condition of this patient remained excellent until the latter part of August, when she developed the symptoms of an acute intestinal obstruction. She was operated on by a surgeon in Canada, but did not survive the operation.

CASE 4.-Mrs. R., aged 56 years, who was admitted to the service of Dr. Halsted, Oct. 19, 1900, had always enjoyed excel lent health until the menopause, six years before. Since then her health has been poor, especially during the past two years, when she began to have edema of the ankles innd continual drowsiness, with now and then severe headaches. Although she had frequently experienced a dull aching pain in the back, there were never any severe attacks until August, 1900, when she was sudklenly seized with a "tearing" pain in the left side, radiating downward into the lower abdomen. Between August and October she had six similar attacks; with the last two, chills and fever. The last attack occurred one week before admission to the hospital. During the paroxysms there was burning pain in the bladder, after which the urine was scanty and highly colored. There was no history of hematuria or the passage of calculi.

The general physical examination was negative. On October 26, at Dr. Halcted's request, Dr. Kelly catheterized the left ureter with a wax-tipped eatheter, which passed readily into the renal pelvis without resistance. Immediately on the stylet being withdrawn turbid urine began to flow : ind, in four minutes 30 c.c. were collected, showing a marked hydronephrosis. The patient was then placed on her right side and pressure over the left kidney caused 5 e.c. more to flow, distinctly more cloudy than the first portion collected: Cultures niade from the urine as it flowed from the catheter showed the infection to be caused by the bacterium coli commune.

The catheter was then withdrawn 3 or $4 \mathrm{~cm}$., and was felt to be grasped and then pass by an obstruction. It was then readily withdrawn and distinet scratch marks ivere seen on the wax tip.

The diagnosis of calculus of the renal pelvis, with associated hydronephrosis, was made on the following points: 1 , scratch marks on the wax tip; 2, gripping of the catheter at a point high up ; 3 , large amount of urine collected in a short time; 4, infected urine. This confirmed the diagnosis which Dr. Halsted had previously made.

Operation, by Dr. Halsted, was performed Oct. 29, 1900-left lumbar nephrotomy.

After laying open the pelvis of the kidney, a careful search of each of the calices failed to reveal a stone. A waxed bougie was then passed down the ureter and was felt to meet an obstruction $27 \mathrm{~cm}$. from the kidney, past which it was gently pushed. On withdrawal distinct stratch marks were found on the wax, demonstrating that the calculus, which had previous!y 
been felt high up, had slipped down to a point only a few centimeters from the vesical opening.

A vaginal examination was then made by Dr. Kelly and a nodule felt, high up in the left fornix. The vaginal wall was friable and broke. down during the examination, allowing the stone to be worked down for a distance of about $4 \mathrm{~cm}$. The ureter was then incised and a rough calculus weighing 2 grs., and measuring $1 \times 0.5 \times 0.4 \mathrm{~cm}$., pulled out by means of a small tenaculum. A gauze drain was inserted into the vagina.

The patient made an excellent recovery. There was leakage of urine into the vagina, abundant at first, but gradually becoming less, and ceasing entirely on the sixteenth day.

\section{DIAGNOSIS.}

Unfortunately the diagnosis of calculus stenosis of the ureter is most difficult. While lumbar pain, associated with anemia and a fixed point of tenderness, may give important clues to this condition, it is often quite impossible to make the differential diagnosis from renal calculus. When the stone can not be felt through the vagina, rectum or abdominal wall, as has been done in thin individuals, there are but two satisfactory means of diagnosis, that of catheterizing the ureters with a bougie tipped with wax, as was done in Cases 1, 3, and 4 , and since successfully employed by Dr. Kelly ${ }^{13}$ in a case recently reported, and that of radiography, which in the hands of a few workers has given most excellent results. When the diagnosis can not be made by any of these means, resort must be had to an exploratory celiotomy, with direct palpation of the ureter, or a lumbar nephrotomy with probing of the ureter.

'The impaction of stones, descending from the kidney, is due not only to their size and irregularity of form, but also to peculiarities of the ureter along its course. giving these well-recognized points of predilection for their arrest: 1 , from 3 to $6 \mathrm{~cm}$. (1 $1 / 5$ to $22 / 5$ inches) from the kidney; 2 , at the point where the ureter crosses the iliac artery; 3 , at, or just above, the vesical orifice of the ureter.

In tabulating 84 operative cases, the position of the stone was found cited in 81. In 19-23.4 per cent.the calculus was located within $6 \mathrm{~cm}$. of the kidney; in 8-9.8 per cent.-at or near the pelvic brim; while 41-50.6 per cent.-were found within $5 \mathrm{~cm}$. (2 inches) of the vesical opening, leaving but 16.2 per cent. for all other locations.

\section{ROUTE FOR REMOVAL OF STONE.}

The route to be selected for the removal of an ureteral stone depends of course upon the position of its impaction. If the calculus is located in the vesical portion of the ureter, i. e.. that portion which traverses the bladder wall, it may be reached per urethram-in the female-the ureteral opening being either dilated or the mucosa slit sufficiently to allow the extraction of the stone. This has been accomplished 7 times, with 1 death. When located low down, within 2 inches of the bladder, the choice is between vaginal ureterotomy, reported in 13 cases, with 1 death; rectal ureterotomy, chosen by $\mathrm{Ceci},{ }^{14}$ whose patient died twenty-six hours after operation; vesical ureterotomy, of which there are recorded 5 cases, with 1 death; or ureterotomy through a perineal incision, done successfully once.

When the calculus is so situated that it can not be reached by any of these operations, the ureter should be exposed by an extraperitoneal incision, a longitudinal slit made in its wall over the stone, which is then extracted, and the incision closed with interrupted fine silk sutures. The possibility, however, of the coexistence of renal calculi, warrants the exploration of the pelvis of the kidney in cases where the extraperitoneal in- cision is sufficiently high to allow the kidney to be brought out of the wound and palpated.

On the other hand, ureterotomy through an abdominal incision is a more dangerous operation, on account of the liability of infection, and less desirable, on account of the possibility of a more troublesome fistula, should a sinus result. Transperitoneal ureterolithotomy has been reported 5 times (including Case 2) with 1 death, whereas in 24 cases in which the route was extraperitoneal, there have been but 3 deaths. In case the diagnosis has been made through an abdominal incision it is advisable to make, as Thornton, ${ }^{15}$ Lloyd $^{16}$ and Morris ${ }^{17}$ have done, a new incision in the lumbar region for the removal of the stone.

When the renal cortex is found to be degenerated and the pelvis and ureter infected, as in Case 1, here reported, nephro-ureterectomy is the most conservative procedure.

While many cases of stone impacted in the ureter have been noted clinically and in post-mortem protocols. a careful search of the literature has revealed but 80 reports of operations for the relief of this condition. A summary of these operations, including the four cases here reported in detail, follows.

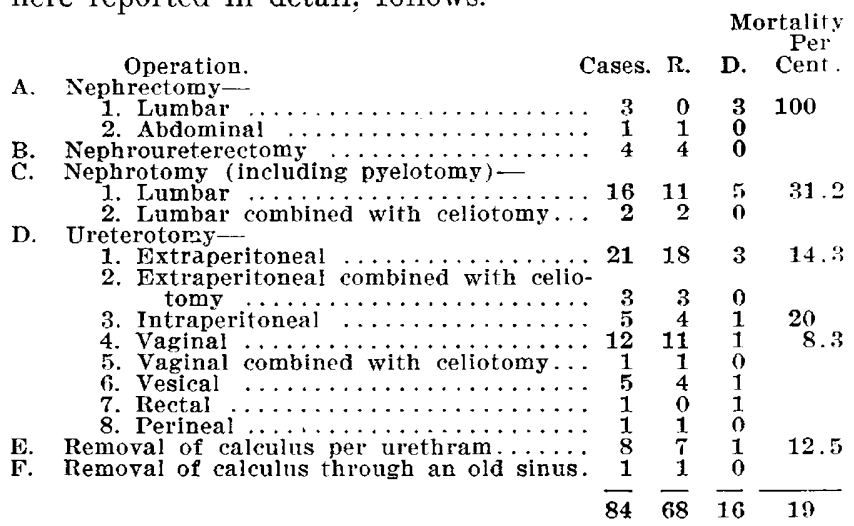

REFEREXCES

1. Morris: Am. Jour. Med. Sci., 1884, vol. 88, p. 458.

2. Bardenhauer: Centralbi. f. Chir., March 25, 1892.

p. 796 .

3. Emmet: Principles and Pract. Gynecology, 1884. 3rd ed.

4. Rawdon: British Med. Jour., 1879. i. p. 152

5. Kirkham: The Lancet, 1889 , i, p. 525.

6. Ralfe and Godlee: Ibid., p. 428 .

7. Twynam: British Med. Jour., 1890, ii, p. 648

8. Cabot: Boston Med. and Surg. Jour., 1890, p. 24t

9. Cullingworth: Trans. Path. Soc., vol. xxxvi, 1885, p. 278.

10. Lane: The lancet, 1890 , ii, p. 967

11. Hall: Medical Record, 1890, vol, 38, p. 430.

12. Cabot: Boston Med. and Surg. Jour., 1890, p. 247: Am. Jour. Med. Sci., 1892, vol. cili, p. 43.

13. Kelly : Jour. Am. Med. Assn., March 3, 1900.

14. Ceci : La Reforma Medica, Sept. 5, 1887.

15. Thornton: Harveian Lectures, 1889.

16. Lloyd: British Med. Jour., 1896, ii, p. 1206

17. Morris: Hunterian Lectures, 1898, p. 77 .

Warm Baths in Cerebrospinal Meningitis.-Dr. Osler is treating cercbrospinal meningitis with warm baths every third hour, and lays great stress in the prognosis on the tendency to relapse, the "intermittent" type of old American writers. There have been 9 deaths in 23 cases treated. No case of men ingitis in typhoid fever has been seen in the Johns Hopkins Hospital. At least 8 different germs have in recent years been reported as the cause of acute rheumatic fever, all of pyogenic origin. Not a single death direetly due to rheumatic fever has occurred in the cliven years since the hospital was opened, yet it is responsible for more deaths than any single fever; 75 per cent. of cases of valvular disease of the heart are its sequels. In Baltimore, in 1899,500 dtaths were attributed to heart disease. The chief indication in the treatment is relief of pain, which is often promptly secured by the salicylates, especially in children. Morphin should be given freely. In protracted cases he looks out for gonococcus infection and arthritis deformans. The salicylates do not protect the heart. 